\title{
Histochemistry for nanomedicine: Novelty in tradition
}

\author{
Manuela Malatesta
}

Department of Neurosciences, Biomedicine and Movement Sciences, University of Verona, Italy

\begin{abstract}
During the last two centuries, histochemistry has provided significant advancements in many fields of life sciences. After a period of neglect due to the great development of biomolecular techniques, the histochemical approach has been reappraised and is now widely applied in the field of nanomedicine. In fact, the novel nanoconstructs intended for biomedical purposes must be visualized to test their interaction with tissue and cell components. To this aim, several long-established staining methods have been re-discovered and re-interpreted in an unconventional way for unequivocal identification of nanoparticulates at both light and transmission electron microscopy.
\end{abstract}

Key words: histochemistry; immunohistochemistry; nanoparticles; light microscopy; transmission electron microscopy.

Correspondence: Manuela Malatesta, Department of Neurosciences, Biomedicine and Movement Sciences, University of Verona, Strada Le grazie 8, 37134 Verona, Italy. E-mail: manuela.malatesta@univr.it 


\section{Introduction}

Since the pioneer book by Francois-Vincent Raspail in $1830,{ }^{1}$ histochemistry has been developing for about two centuries, playing a primary role in biological and medical research. By revealing in situ the molecular organization of cell and tissue, histochemistry has indeed provided significant advancements in the knowledge in many fields of life sciences. ${ }^{2,3}$

At the end of the last century, in parallel with the great development of biomolecular techniques, histochemistry has become progressively neglected, being perceived by non-histochemists as a merely descriptive and old-fashioned approach (the term histochemistry being "commonly perceived as an archaic term primarily associated with stains and staining techniques", in Raimond Coleman's words) ${ }^{4}$ However, fashions change and, during the last decade, histochemical techniques have been reappraised. In fact, the knowledge of the chemical composition and molecular interactions of chemical species in a biological system must be supported by the information on the location and dynamics of specific molecules in cells and tissues. Histochemistry is nowadays more and more oriented toward the detection of single molecules in the very place where their structural and functional roles are exerted. ${ }^{5}$

It is worth noting that histochemical stainings and techniques that were introduced in the first years of the $20^{\text {th }}$ century or even before are still routinely used as irreplaceable tools to detect different substances in situ. ${ }^{6}$ The Perls' Prussian blue method was introduced in $1867^{7}$ and still is the method of choice for visualizing iron; classical histochemical techniques to demonstrate the presence of lipids ${ }^{8}$ or polysaccharides ${ }^{9}$ are still popular; Von Kossa's method $^{10}$ to demonstrate the presence of calcium deposits in tissues was developed in 1901 and is presently employed to study the process of mineralization. Remarkably, its long-term impact on life sciences and medicine still places histochemistry at the research forefront in these disciplines.

As a matter of fact, classical histochemical methods have recently been applied in the relatively new and fast-developing field of nanomedicine where the novel nanoconstructs for biomedical purposes must be visualized to test their interaction with various biological systems (from cells in culture, to explanted tissues, to living animals $\left.{ }^{11-15}\right)$.

In the attempt to identify the nanoparticulates inside organs, tissues and cells, researchers re-discovered and re-interpreted in an innovative way several long-established staining methods for unambiguous identification of their molecular constituents at both light microscopy and transmission electron microscopy (TEM).

\section{Histochemistry for nanomedical research}

The most common method to make visible a nanoconstruct at light microscopy consists in loading/linking a fluorescent dye during the synthetic process. Fluorescently labelled nanoparticles may be visualized at both bright-field microscopy and TEM by applying the procedure of diaminobenzidine (DAB) photooxidation. This histochemical method was proposed by Maranto in $1982^{16}$ to convert the fluorochrome signal into a stable reaction product visible at bright-field microscopy as a brownish pigment and at TEM as an electron dense granular precipitate. DAB photooxidation proved to be suitable for different types of nanoparticles conjugated with different fluorophores, allowing their detection in the intracellular milieu even after long time from their uptake. ${ }^{17-21}$

Fluorochrome labelling of nanoconstructs cannot sometimes be used due to technical or experimental reasons: e.g., the rapid loss of the loaded fluorophore in the biological environment may make the nanoparticles undetectable; or fluorophore addition may alter the original physicochemical properties; or high tissue autofluorescence is incompatible with fluorochrome labelling of the nanoparticles. In all these cases, histochemical staining techniques may provide suitable detecting solutions.

Iron-, gold- or, more generally, metal-based nanoconstructs are easily observed at TEM, due to their intrinsic electron density that makes them unequivocally recognizable in the biological environment (for a recent review $\mathrm{see}^{22}$ ). However, these nanoparticles have no intrinsic feature that may make them visible at light microscopy.

Prussian blue staining has frequently been used to visualize at bright field microscopy iron-based nanoparticles inside cultured cells or tissue slices. ${ }^{23-28}$ After treatment with an acidic solution of potassium ferricyanide, iron in the ferric state gives rise to a bright blue pigment called 'Prussian blue" (ferric ferrocyanide). The blue pigment can be transformed into a brown-stained product by irradiation with ultraviolet light: this is an especially convenient procedure to improve the detection of low number of iron-based nanoparticles. ${ }^{29}$ Gold nanoconstructs may be seen at light microscopy by applying the silver-enhancement technique: the deposition of silver on the gold particles makes them grow in size and become visible under a standard bright-field microscope. ${ }^{30-33}$

Organic nanoconstruct are especially difficult to detect especially at TEM, where they can hardly be discriminated from the cell or tissue environment, due to their low intrinsic electron density.

The critical-electrolyte-concentration Alcian blue method was originally proposed in 1975 by Schofield et al. to reveal glycosaminoglycans in tissue sections, ${ }^{34}$ and was recently repurposed, in the frame of a nanomedical study, to label with high efficiency and specificity hyaluronic acid-based nanoparticles ${ }^{35}$ inside cultured cells at both bright field microscopy (as a blue product) and TEM (as fine electron dense precipitates). ${ }^{36}$ Alcian blue has also been used to detect nanoscaled dendritic polyglycerol sulfate amine in liver after in vivo injection thanks to the affinity of this dye for the negatively charged sulfate groups. ${ }^{37}$

Various histochemical methods have been proposed to label lipid-based nanoparticles, depending on their chemical nature. Osmium tetroxide is an efficient, long-established fixative for lipid molecules thanks to its addition to the double carbon-carbon bonds of unsaturated fatty acids ${ }^{38,39}$ and can also be used as a "dye": the deposition of metallic osmium in the lipid-containing structures results in an intense brownish or black color at bright-field microscopy, and gives a marked electron density at TEM. Consequently, lipid-based nanoparticles have frequently been visualized by osmium tetroxide. ${ }^{21,40-44}$ Lipid nanoparticles have also been made visible at light microscopy by staining with PKH67: this is a fluorescent dye for specific and long-lasting labelling of cell membrane thanks to its long aliphatic tails that ensures stable incorporation into the lipid membrane regions..$^{43,45}$ An interesting approach to allow visualization of liposomes in three-dimensional optical microscopy has been set up by Syed et $a l{ }^{46}$ : to solve the problem of lipid denaturation in cleared tissues, they developed cross-linkable tags that remain attached to the liposome surface in living organs but, when the tissue undergoes fixation, they become cross linked into the tissue, thus revealing the distribution of liposomes.

Rare-earth-based nanoparticles have been visualized at brightfield microscopy in both cultured cells and tissue slices by means of a chromogenic reaction with Chlorophosphonazo III, which gives rise to a blue product independently of the rare earth type, and can be quantitatively evaluated. ${ }^{47}$

Besides "classical" histochemical staining methods, immunohistochemistry too has been used to investigate nanoparticulates 
designed for biomedical applications. Immunogold labelling allowed the intracellular localization at TEM of nanocarriers loaded with digoxigening-containing $\mathrm{DNA}^{48}$ as well as the unequivocal detection of nanovesicles by targeting membrane markers. ${ }^{49-51}$ Chitosan nanoparticles were detected at both fluorescence microscopy and TEM by immunolabelling the loaded drug, tracking also its release in the intracellular compartments. ${ }^{52}$

\section{Concluding remarks}

The above examples are evidence that histochemistry is far from being outdated but still has many responses to give, even in cutting-edge research fields. In nanomedicine, histochemists will find stimulating challenges to test their skill and creativity: established staining techniques will surely find novel applications, and the innovative materials used to manufacture the nanoconstructs will encourage the development of original staining protocols.

Once again, histochemistry will prove to be alive and kicking.

\section{References}

1. Raspail FV. [Essai de chimie microscopique appliquée à la physiologie, ou l'art de transporter le laboratoire sur le porteobjet dans l'étude des corps organisés].[Book in French]. Paris: Meilhac; 1830.

2. Wick MR. Histochemistry as a tool in morphological analysis: a historical review. Ann Diagn Pathol 2012;16:71-8.

3 Yadav V, Arif N, Singh VP, Guerriero G, Berni R, Shinde S, et al. Histochemical techniques in plant science: More than meets the eye. Plant Cell Physiol 2021;62:1509-27.

4. Coleman R. Histochemistry in the new millennium: a time to change our terminology? Acta Histochem 2000;102:241-6.

5. Pellicciari C, Biggiogera M. Histochemistry of single molecules. New York: Springer; 2017.

6. Coleman R. The impact of histochemistry - A historical perspective. Acta Histochem 2000;102:5-14.

7. Perls M. [Nachweis von Eisenoxyd in gewissen Pigmenten].[Article in German]. Virchows Arch Path Anat 1867;39:42-8.

8. Daddi L. [Nouvelle méthode pour colorer la graisse dans les tissues].[Article in French]. Arch Ital Biol 1896;26:143-6.

9. McManus JFA. Histological and histochemical uses of periodic acid. Stain Technology 1948;23:99-108.

10. von Kossa J. [Über die im Organismus künstlich erzeugbaren Verkalkungen].[Article in German]. Beitr Path Anat 1901;29:163-202.

11. Carton F, Calderan L, Malatesta M. Incubation under fluid dynamic conditions markedly improves the structural preservation in vitro of explanted skeletal muscles. Eur J Histochem 2017;61:2862.

12. Khan A, Waqar K, Shafique A, Irfan R, Gul A. In vitro and in vivo animal models: The engineering towards understanding human diseases and therapeutic interventions. In: Barh D, Azevedo V, editors. Omics technologies and bio-engineering towards improving quality of life. Cambridge: Academic Press; 2017. p. 431-48.

13. Segeritz CP, Vallier L. Cell culture: Growing cells as model systems in vitro. In: Jalali M, Saldanha FYL, Jalali M, editors. Basic science methods for clinical researchers. Amsterdam: Elsevier; 2017. p. 151-72.

14. Corrò C, Novellasdemunt L, Li VSW. A brief history of organoids. Am J Physiol Cell Physiol 2020;319:C151-65.
15. Cappellozza E, Zanzoni S, Malatesta M, Calderan L. integrated microscopy and metabolomics to test an innovative fluid dynamic system for skin explants in vitro. Microsc Microanal 2021;27:923-34.

16. Maranto AR. Neuronal mapping: a photooxidation reaction makes Lucifer yellow useful for electron microscopy. Science 1982;217:953-5.

17. Malatesta M, Giagnacovo M, Costanzo M, Conti B, Genta I, Dorati R, et al. Diaminobenzidine photoconversion is a suitable tool for tracking the intracellular location of fluorescently labelled nanoparticles at transmission electron microscopy. Eur J Histochem 2012;56:e20.

18. Malatesta M, Zancanaro C, Costanzo M, Cisterna B, Pellicciari C. Simultaneous ultrastructural analysis of fluorochromephotoconverted diaminobenzidine and gold immunolabelling in cultured cells. Eur J Histochem 2013;57:e26.

19. Malatesta M, Pellicciari C, Cisterna B, Costanzo M, Galimberti V, Biggiogera $\mathrm{M}$, et al. Tracing nanoparticles and photosensitizing molecules at transmission electron microscopy by diaminobenzidine photo-oxidation. Micron 2014;59:44-51.

20. Malatesta M, Grecchi S, Chiesa E, Cisterna B, Costanzo M, Zancanaro C. Internalized chitosan nanoparticles persist for long time in cultured cells. Eur J Histochem 2015;59:2492.

21. Costanzo M, Scolaro L, Berlier G, Marengo A, Grecchi S, Zancanaro $\mathrm{C}$, et al. Cell uptake and intracellular fate of phospholipidic manganese-based nanoparticles. Int J Pharm 2016;508:83-91.

22. Malatesta M. Transmission electron microscopy as a powerful tool to investigate the interaction of nanoparticles with subcellular structures. Int J Mol Sci 2021;22:12789.

23. Stelter L, Pinkernelle JG, Michel R, Schwartländer R, Raschzok N, Morgul MH, et al. Modification of aminosilanized superparamagnetic nanoparticles: feasibility of multimodal detection using 3T MRI, small animal PET, and fluorescence imaging. Mol Imaging Biol 2010;12:25-34.

24. van Landeghem FK, Maier-Hauff K, Jordan A, Hoffmann KT, Gneveckow U, Scholz R, et al. Post-mortem studies in glioblastoma patients treated with thermotherapy using magnetic nanoparticles. Biomaterials 2009;30:52-7.

25. Bumb A, Regino CA, Egen JG, Bernardo M, Dobson PJ, Germain RN, et al. Trafficking of a dual-modality magnetic resonance and fluorescence imaging superparamagnetic iron oxide-based nanoprobe to lymph nodes. Mol Imaging Biol 2011;13:1163-72.

26. van Tilborg GA, Cormode DP, Jarzyna PA, van der Toorn A, van der Pol SM, van Bloois L, et al. Nanoclusters of iron oxide: effect of core composition on structure, biocompatibility, and cell labeling efficacy. Bioconjug Chem 2012;23:941-50.

27. Tefft BJ, Uthamaraj S, Harbuzariu A, Harburn JJ, Witt TA, Newman B, et al. Nanoparticle-mediated cell capture enables rapid endothelialization of a novel bare metal stent. Tissue Eng Part A 2018;24:1157-66.

28. Ring HL, Gao Z, Sharma A, Han Z, Lee C, Brockbank KGM, et al. Imaging the distribution of iron oxide nanoparticles in hypothermic perfused tissues. Magn Reson Med 2020; $83: 1750-9$

29. Frank JA, Kalish H, Jordan EK, Anderson SA, Pawelczyk E, Arbab AS. Color transformation and fluorescence of Prussian blue-positive cells: implications for histologic verification of cells labeled with superparamagnetic iron oxide nanoparticles. Mol Imaging 2007;6:212-8.

30. Rayavarapu RG, Petersen W, Ungureanu C, Post JN, van Leeuwen TG, Manohar S. Synthesis and bioconjugation of gold nanoparticles as potential molecular probes for light- 
based imaging techniques. Int J Biomed Imag 2007;2007: 29817.

31. Kim D, Jeong YY, Jon S. A drug-loaded aptamer-gold nanoparticle bioconjugate for combined CT imaging and therapy of prostate cancer. ACS Nano 2010;4:3689-96.

32. Centi S, Tatini F, Ratto F, Gnerucci A, Mercatelli R, Romano $\mathrm{G}$, et al. In vitro assessment of antibody-conjugated gold nanorods for systemic injections. J Nanobiotechnology 2014;12:55.

33. Heidari Z, Sariri R, Salouti M. Gold nanorods-bombesin conjugate as a potential targeted imaging agent for detection of breast cancer. J Photochem Photobiol B 2014;130:40-6.

34. Schofield BH, Williams BR, Doty SB. Alcian Blue staining of cartilage for electron microscopy. Application of the critical electrolyte concentration principle. Histochem J 1975;7:139-49.

35. Carton F, Chevalier Y, Nicoletti L, Tarnowska M, Stella B, Arpicco S, et al. Rationally designed hyaluronic acid-based nano-complexes for pentamidine delivery. Int $\mathrm{J}$ Pharm 2019;568:118526.

36. Carton F, Repellin M, Lollo G, Malatesta M. Alcian blue staining to track the intracellular fate of hyaluronic-acid-based nanoparticles at transmission electron microscopy. Eur J Histochem 2019;63:3086.

37. Holzhausen C, Gröger D, Mundhenk L, Welker P, Haag R, Gruber AD. Tissue and cellular localization of nanoparticles using $35 \mathrm{~S}$ labeling and light microscopic autoradiography. Nanomedicine 2013;9:465-8.

38. Khan AA, Riemersma JC, Booij HL. The reactions of osmium tetroxide with lipids and other compounds. J Histochem Cytochem 1961;9:560-3.

39. Korn ED. A chromatographic and spectrophotometric study of the products of the reaction of osmium tetroxide with un-saturated lipids. J Cell Biol 1967;34:627-38.

40. Bello V, Giovanni G, Mazzoldi P, Vivenza N, Gasco P, Idee JM, et al. Transmission electron microscopy of lipid vesicles for drug delivery: comparison between positive and negative staining. Microsc Microanal 2010;16:456-61.

41. Costanzo M, Carton F, Marengo A, Berlier G, Stella B, Arpicco S, et al. Fluorescence and electron microscopy to visualize the intracellular fate of nanoparticles for drug delivery.
Eur J Histochem 2016;60:2640.

42. Costanzo M, Malatesta M. Embedding cell monolayers to investigate nanoparticle-plasmalemma interactions at transmission electron microscopy. Eur J Histochem 2019;63:3026.

43. Costanzo M, Esposito E, Sguizzato M, Lacavalla MA, Drechsler M, Valacchi G, et al. Formulative study and intracellular fate evaluation of ethosomes and transethosomes for vitamin D3 delivery. Int J Mol Sci 2021;22:5341.

44. Sguizzato M, Ferrara F, Hallan SS, Baldisserotto A, Drechsler M, Malatesta M, et al. Ethosomes and transethosomes for mangiferin transdermal delivery. Antioxidants (Basel) 2021;10:768

45. Mousseau F, Berret JF, Oikonomou EK. Design and applications of a fluorescent labeling technique for lipid and surfactant preformed vesicles. ACS Omega 2019;4:10485-93.

46. Syed AM, MacMillan P, Ngai J, Wilhelm S, Sindhwani S, Kingston BR, et al. Liposome imaging in optically cleared tissues. Nano Lett 2020;20:1362-9.

47. Huang J, Hou Y, Ma T, Zhang P, Li Y, Liu C, et al. A Novel histochemical staining approach for rare-earth-based nanoprobes. Adv Therap 2018;1:1800005.

48. Cartier R, Velinova M, Lehman C, Erdmann B, Reszka R. Ultrastructural analysis of DNA complexes during transfection and intracellular transport. $\mathrm{J}$ Histochem Cytochem 2003;51:1237-40.

49. Romancino DP, Paterniti G, Campos Y, De Luca A, Di Felice $\mathrm{V}$, d'Azzo A, et al. Identification and charac-terization of the nano-sized vesicles released by muscle cells. FEBS Lett 2013;587:1379-84.

50. Geeurickx E, Tulkens J, Dhondt B, Van Deun J, Lippens L, Vergauwen $\mathrm{G}$, et al. The generation and use of recombinant extracellular vesicles as biological reference material. Nat Commun 2019;10:3288.

51. Varderidou-Minasian S, Lorenowicz MJ. Mesenchymal stro$\mathrm{mal} / \mathrm{stem}$ cell-derived extracellular vesicles in tissue repair: challenges and opportunities. Theranostics 2020;10:5979-97.

52. Malatesta M, Galimberti V, Cisterna B, Costanzo M, Biggiogera M, Zancanaro C. Chitosan nanoparticles are efficient carriers for delivering biodegradable drugs to neuronal cells. Histochem Cell Biol 2014;141:551-8.

Received for publication: 22 December 2021. Accepted for publication: 23 December 2021.

This work is licensed under a Creative Commons Attribution-NonCommercial 4.0 International License (CC BY-NC 4.0).

(C) Copyright: the Author(s), 2021

Licensee PAGEPress, Italy

European Journal of Histochemistry 2021; 65:3376

doi:10.4081/ejh.2021.3376 